\title{
A Study of End-Users' Attitudes towards Digital Media Approach: the Experience of a Public University in Uganda
}

\author{
Ndawula Stephen $(\mathrm{PhD})$ \\ Faculty of Education Kyambogo University, Uganda \\ E-mail: stendawula@yahoo.com \\ Ngobi David Henry \\ Faculty of Education Kyambogo University, Uganda \\ Namugenyi Deborah \\ Faculty of Education Kyambogo University, Uganda \\ Nakawuki Rose Coaster \\ School of Education Makerere University, Uganda
}

Received: June 12, 2012

Accepted: September 4, 2012

Online Published: September 5, 2012

doi:10.5430/ijhe.v1n2p150

URL: http://dx.doi.org/10.5430/ijhe.v1n2p150

\begin{abstract}
University students in Uganda had been confined to use of traditional educational technologies such as chalkboards, papers and text books. Digital Media Approach recently found its way in the academia at public universities in Uganda. Information and communication technology (ICT) have become popular means of surfing, downloading and obtaining electronic materials among students. The approach has globally facilitated the seeking of academic information at institutions of higher learning in Uganda. However, little research has been conducted in regard to students who are the key users of Digital Media. The purpose of this study was to explore students' attitudes towards Digital Media Approach at a public university in Uganda. The study specifically sought to establish whether university students' attitudes towards digital technology were dependent on computer ownership, field of study and previous computer hands-on experience. A survey research was employed to establish students' attitudes in regard to digital media. Questionnaires and interviews were used as tools for data collection while data was analyzed using a t-test. The findings showed that students who had their own computers as well as previous computer hands-on experience had more positive attitudes towards using the media than their counterparts without previous computer hands-on experience.
\end{abstract}

Keywords: Attitudes, Digital Media Approach, Media Ownership, Field of Study and previous computer hands-on experience

\section{Background}

Educational technology at universities in Uganda has been strengthened to meet the current demands and expectations of Higher education. Higher education is challenged by new opportunities related to technologies for accessing academic information by students. The use of technology to enhance student learning in universities is an important area for discussion and study within the field of educational technology. Information and communication technology (ICT) resources are among the emerging technologies in the education system (Mukwa et al, 2008 and UNESCO, 2000).

Uganda developed its initial ICT national policy in 2003. The policy framework document that delineated the need for a national ICT policy recognized that Uganda would need to embrace the goal of lifelong education for all. One of the recommendations that was implemented early in 2006 resulted into the founding of a Ministry of ICT to address the convergence of ICT and to provide coordination of policy development (Guyana, 2006 and Infodev et al, 2007). New media for providing quality educational materials was realized in response- the digital media. 
Kyambogo is the second largest University in Uganda established in 2003 as a Public University. Kyambogo University (KYU) has educational ICT projects to facilitate teaching and learning. They include a website, Intranet web servers, laboratories and computers with wireless connectivity. The university has also made progress in digital media and Internet supported distance learning through the Open, Distance and e-Learning (ODeL).

Successful adaptation of technologies in any form of institution is end-users' acceptance, which in turn might be greatly influenced by attitudes. For this reason, it is necessary to study students' attitudes toward the Digital Media Approach (DMA) in KYU. Students' attitudes towards digital media are widely recognized as a necessary condition for effective use of the technology in the academia (Louise, et al, 2008 and Asan, et al, 2006). DMA addresses sorts of electronic resources such as digital audio, digital video, computer games, internet technology, communication (email) and social interaction.

Various broadband initiatives have been launched and the number of African countries offering commercial Asymmetric Digital Subscriber Line (ADSL) reached 21 in 2005. Wireless access technologies are increasingly used as a substitute to traditional devices especially in the countryside. A series of experiments of digital media are going on which is expected to deliver a major boost to connectivity in African universities, (InternetWorldStats. com, 2006).

A study from School Net Africa (SNA) examined the training of African students in ICT before and after they entered classrooms, and observed that due to lack of familiarity with computers, students do not know how to browse and find relevant academic materials. While digital media approach is growing steadily most African universities, user attitude is still very low due to the low attitudes (SNA, 2004).

\section{Problem Statement}

The approach to digital media was introduced in KYU to assist students in their academic tasks. The media allows both students and lecturers the luxury of communication with each other from any location. However, students have tended to preserve the benefits related to the traditional (non-electronic) classroom learning; whilst may as well feel increasing pressure to experiment with the use digital media. Factors to digital media approach need to be established since it is difficult for the university to know if they are meeting the academic needs of students effectively (OECD, 2005). It is against the aforementioned concern that this study attempted to explore students' attitudes towards digital media approach in KYU.

This study was carried out to establish how computer ownership, field of study and previous hands on experience with the computer affects students' attitudes towards Digital Media Approach in KYU. Research was carried out in accordance with three objectives namely:-

i) To establish if ownership of a computer affects students' attitudes towards digital media approach.

ii) To establish if field of study affects students' attitudes towards digital media approach.

iii) To establish if previous computer hands on experience had an impact on students' attitudes towards digital media approach.

\section{Methodology}

A survey research that was predominantly quantitative was conducted in KYU; one of the public universities in Uganda. Three hundred and fifty undergraduate students, who were in the final year of their course, were used as respondents. Third year students were randomly selected as they were due to complete their curriculum that required use of digital media. Further these students had a longer hands-on experience since they had more lessons on their time table that exposed them to the digital media approach to teaching and learning in the university.

\subsection{Procedure and Instrumentation}

The researchers sought permission from the office of the Academic Registrar, Kyambogo University, to carry out data collection from the university. Documented permission was granted through an official letter. The researchers identified some research assistants to help in data collection on the criteria of having experience in information technology. The research assistants had been instructors of ICT in KYU for long. A brief guidance of which included descriptions of what the study was all about was carried out to the research assistants. Instruments for data collection were questionnaires and interviews. Actual data collection was begun after pre-testing the questionnaires on third year students from a nearby public university.

Actual data collection was done by distributing questionnaires throughout the university to three hundred and fifty students. Inspite of a highly satisfactory response rate of $83 \%$, ten of the questionnaire were discarded as they were incomplete. Consequently, two hundred eighty questionnaires were used for data analysis. 


\subsubsection{Questionnaires}

The questionnaire was a Likert-type that included thirty six items positively worded. It had a rating scale with three disagree -or- agree response choices: Disagree (D), Neutral (N) and Agree (A). A negative response (i.e. Disagree) was allocated a score of 1, Neutral given a value of 2 and positive responses (i.e. Agree) assigned a value of 3. A high score indicated a positive attitude, whereas a low score signified a negative attitude.

\subsubsection{Interviews}

The interviews assisted the researchers to elicit reflective responses that went further than the type of surface responses typically yielded by the questionnaires so as to give an opportunity for probing into answers given by the students.

\subsection{Data Analysis}

The questionnaire contained items about computer ownership, previous computer hands-on experience and field of study. A t-test was regarded most suitable since the study involved an evaluation of differences in means between two groups for each research question. For instance, ownership of a computer had students with and without computers, field of study comprised of computer-based and non computer-based courses while previous computer hands-on experience comprised of respondents with and without prior experience as reflected in table 1. In such a scenario, a-test was most appropriate for comparing mean (Wong et al, 2007).

\section{Insert Table 1 here}

\section{Results and Discussions}

Three research questions were employed to study the relationship between Media ownership, previous computer hands-on experience and field of study and students' attitudes towards digital media approach in KYU. These were the three independent variables influencing students' attitudes digital media approach. The results were therefore analyzed and discussed in relation to the research questions indicated below:-

\subsection{Research Question One:}

Do students' attitudes towards Digital Media approach in KYU depend on having a personal computer?

In response to research question one, the results showed that students who had personal computers had positive attitudes towards digital media approach as seen in table 2 .

\section{Insert Table 2 here}

According to t-test results that were done for having a personal computer among respondents; as indicated above, the $\mathrm{p}$-value is lower than the standard value that is, $0.05>0.005$. The results showed that respondents with personal computers have higher mean score in attitudes than those without. Students with personal computers expressed more positive attitudes compared to their counterparts without personal computers. This therefore, suggests that attitudes of respondents towards digital media approach are dependant on computer ownership.

In addition, data from the interviews also indicated that students who owned computers had positive attitudes towards use of digital media in the teaching and learning as opposed to those without personal computers. One student with a personal computer had this to say:

I feel I am at an advantage because I have my own laptop. I am able to search information from anywhere with my laptop without traveling long distances. I can easily do my coursework from the hostel at anytime. Since I am interested in using the Internet, I am able to surf even in the late night hours when the network tends to be less congested.

In agreement with the above finding, Olsen, (2000) also contends that owning a personal computer improves on students' access and use of digital media, thus positive attitudes. Kent et al (2005) and Usun (2003) also observed that students without personal computers had little interest in digital media approach to teaching and learning. Thus, it can be concluded that the KYU students' attitudes towards digital media approach is dependent on having a personal computer.

\subsection{Research Question Two:}

Does field of study affect students' attitudes towards Digital Media approach?

The results in response to research question two showed that students whose courses involved using computers exhibited more positive attitudes than those whose courses did not use computers during the teaching learning process. Table 3 provides results from a t-test: 
Insert Table 3 here

In Table 3, a total of 280 students completed the questionnaires to show an attitude difference based on field of study. The means of responses by the students towards questions based on their fields of study were tested using a t-test method. One hundred and forty (140) respondents from courses involving use of computers and another one hundred and forty (140) respondents from courses that do not involve use of computers had means of 17.9143 and 16.4929 respectively. The t-test revealed a p-value of .002 and a t-value of 3.171. Since the p-value of 0.002 is less than 0.05 , the alpha level of significance, the findings show that field of study influences students' attitudes towards use of digital media, whereby students from courses involving use of computers had more favorable attitude than those whose courses do not involve use of computers.

Further, the results from interviews also supported those from questionnaires whereby students whose courses provided them the opportunity to use computers in the day-to-day lessons had more favorable attitude than those whose courses did not involve use of computers. One student from an ICT related course was quite explicit in expressing his interest in digital media by stating:

My interest in digital media approach is high due to the nature of my course content that guides me on how to search and find pretty good sources. It's up to me to pick from famous search engines on the net. They are trustworthy and I know what types of sources they are. There is a big percentage of the software I have downloaded on my computer necessary for my syllabus.

Interview results related to research question two also support the argument that using ICT in studying particular courses improves on students' attitudes towards digital media approach.

The findings of the study are in agreement with Hong et al (2003) who assert that when student apply computer skills in their courses, it is of great importance in performing academic tasks. This study clearly spelt out that field of study had an impact on the use of digital media by improving on students' attitude. It is evidently clear that students' field of study has an influence students' use of Digital Media.

\subsection{Research question Three}

Does previous computer hands-on experience contribute to students' attitudes towards Digital Media approach?

In an attempt to answer this research question, data was collected concerning the relationship between having previous computer hands-on experience and students' attitudes towards digital media as shown in table 4.

Insert Table 4 here

According to t-test results that were done for having previous computer hands-on experience among students as indicated in table 4 , the p-value is lower than the pre-determined level of significance, $(0.05>0.000)$. The results show that respondents with previous computer hands-on experience had higher mean score in attitudes than those without. Having previous computer hands-on experiences improves on students' attitudes towards Digital Media approach.

Results from the interviews also indicated that students who had previous computer hands-on experiences expressed high interest in electronic media use. This was also partly dependent upon the fact that these students came from secondary schools offering computer education and had at least received training in ICT. One student who had done computer studies during his secondary school education commented:

It is valuable to have computer ICT skills prior to use of digital media. These skills have helped me to pick interest in the use to computer materials to complement library service. Even though in our lessons we often use digital media to seek and get hold of information, without previous computer hands-on experience, it would be hard for me to succeed. My computer experience at secondary school makes me more confident and accurate when typing and browsing.

Interviews indicated that previous computer hands-on experiences influence students' attitudes towards digital media approach to learning and teaching. It was evident that students who had received some computer skills before joining KYU were more confident when using electronic media. Successful experience using computer motivated students to use digital media in learning and classrooms activities.

In agreement with the above finding, Luan et al, (2005) and Rugayah et al (2004) also assert that students' use of digital media is highly dependent on previous computer hands-on experience. Further, Schumacher et al (2001) in their finding also observed that students who had prior computer hands-on experience were highly motivated in the application of digital media approach to learning. 


\section{Conclusions}

- The first research question in this study concerned having a personal computer and students' attitudes towards digital media approach. Here, a relationship between having a personal computer and students' attitudes towards digital media was realized. It can be concluded that having a personal computer increases students' access to ICT; and students with them tend to have positive attitudes towards digital media approach.

- Relationship between students' previous computer experience and attitudes towards digital media approach was verified. From the results of research question two, students who had previous computer hands-on experience exhibited higher confidence in digital media use than their counterparts without prior skills. Students with previous computer hands-on experience stood better opportunities; and could use superior techniques for computer use than those without. It can be concluded that having previous computer hands-on experience improves on students' attitudes towards digital media approach.

- Field of study was found to impact on students' attitudes towards digital media approach in KYU. Students from ICT-based courses tended to use digital media to accomplish academic tasks more frequently than their counterparts from the non ICT-based courses. Students under ICT-based field of study expressed positive attitudes towards digital media approach.

\subsection{Implications}

This study contributes much in providing a baseline evidence to monitor circumstances surrounding digital media approach, and in particular the developing world. Basing on the findings and conclusions of this study, the following recommendations are made:

1) It is worth noting here that one very important factor in this study is the issue of computer ownership. Computer ownership is one of the variables that many researchers have intensively investigated and found to be a significant factor that influences attitudes towards digital media use among students. For that matter, at public universities there is need to devise a policy in which students are provided with personal computers at subsidized prices. Ideally, students' loan schemes can also be initiated to enable students acquire personal computers.

2) KYU students, as ardent users of digital media have to meet the challenge of demonstrating more acceptable, useful and affordable ways of integrating ICT into their day-to-day teaching and learning activities. Therefore, the university management should first orient all newly admitted students to use of digital media in order to develop positive attitudes toward the technology

3) Further, it has been observed that much of the hesitancy about digital media use among students is due to lack of previous experience with ICT tools. Therefore Secondary schools are advised to equip their students with digital materials to prepare them for adaptation of ICT at university. The secondary school ICT syllabus in Uganda should be revisited to include ICT.

\section{References}

Asan, A and Koca, N. (2006). An Analysis of Students' Attitudes Towards Internet: Current Developments in Technology-Assisted Education. Sultan Qaboos University, College of Education, ILT Department, Muscat, Sultanate of Oman.

GUYANA. (2006). National Strategy final draft, Internet Scout 1994 2008. [Online] Available: http://webmail2.uis.edu/exchweb/bin/redir.asp?URL=http://scout.wisc.edu/ retrieved on $10^{\text {th }} \mathrm{Feb} 2008$

Hong, K. S., Ridzuan, A. A., \& Kuek, M. K. (2003). Students' attitudes toward the use of the Internet for learning: A study at a university in Malaysia. Educational Technology \& Society, 6 (2), 45-49.

Infodev, Andrew, \& Tanestik. (2007). ICT for Africa, Country report, Briefing Papers. [Online] Available: http://www.jisc.ac.uk/mle/reps/briefings

InternetWorldStats.com. (2006). [Online] Available: http://www.internetworldstats.com/af/ug.htm as retrieved on 11 Feb 2007

Junni, P. (2007). Students seeking information for their Masters' theses: the effect of the Internet. Information Research, 12(2) paper 305. [Online] Available: http://InformationR.net/ir/12-2/paper305.html

Louise, Story and comScore. (2008). "They Know More Than You Think" (JPEG), March 10, 2008. in Story, Louise. "To Aim Ads, Web Is Keeping Closer Eye on You", The New York Times, The New York Times Company, March 10, 2008. 
Mukwa, C, Wanjala M. S. M and Too J. K. (2008). ICT And Innovative Classroom Practice: Factors Underlying Mathematics Teachers' Attitudes Towards The Integration of Computer In Teaching. Paper presented at the 4th Annual International Conference- 2008, Moi University.

OECD. (2005). E-learning in tertiary education: where do we stand? Education \& Skills, vol. 2005, no. 4, pp. 1-293 [Online] Available: http://www.caos.nl/ocw/doc/Preliminary_Findings2.pdf Accessed on 26 April 2006.

Olsen, F. (2000, 18 October). Massachusetts May Require All Public College Students To Own Computers, Chronicle Of Higher Education, 8, December 2000. [Online] Available: http://chron-icle.com/daily /2000/10/2e000101801t.htm.

Pennanen, M \& Vakkari, P. (2003). Student's conceptual structure, search process and outcome while preparing a research proposal: a longitudinal case study. Journal of the American Society for Information Science and Technology, 54(8), 759-770.

Rugayah Hajah Hj. Hashim \& Wan Narita Mustapha. (2004). Attitudes Toward Learning About And Working with Computers Of Students. The Turkish Online Journal of Educational Technology - TOJET, Volume 3, Issue 2, April, 2004.

Schumacher P and Morahan-Martin. J. (2001). Gender, Internet and computer attitudes and experiences. Computers in Human Behavior. Elsevier Science, Volume 17, Issue 1, Pp. 95-110.

UNESCO. (2000). World Communication and Information Report 1999-2000.

Universities and other Tertiary Institutions Act. (2001), Kampala Uganda.

Usun Salih. (2003a). Uses of Internet in the World and Turkey: A Comparative Review. Turkish Online Journal of Distance Education-TOJDE, Volume4, Number 3, July, 2003.

Wong, S. L., \& Hanafi, A. (2007). Gender Differences in Attitudes towards Information Technology among Malaysian Student Teachers: A Case Study at University Putra Malaysia. Educational Technology \& Society, 10 (2), 158-169.

World Bank. (2001). A Chance to Learn: Knowledge and Finance for Education in Sub-Saharan Africa (Washington: World Ban k, Sector Assistance Strategy, Regional Hum an Development Family, Africa Region, 2001), p. 52.

Table 1. Summary two groups of respondents for each research question $(\mathrm{N}=280)$

\begin{tabular}{|l|l|l|}
\hline Summarized Independent & Groups of Respondents & N \\
\hline \multirow{4}{*}{ Having a personal computer? } & With Personal Computers & 128 \\
\cline { 2 - 3 } & Without Personal Computers & 152 \\
\hline Field of Study & ICT-based courses & 140 \\
\cline { 2 - 3 } & Non ICT-based courses & 140 \\
\hline \multirow{2}{*}{ previous computer hands-on experience } & With Prior experience & 205 \\
\cline { 2 - 3 } & Without Prior experience & 75 \\
\hline
\end{tabular}


Table 2. Relationship between having a personal computer and attitudes towards digital media approach

\begin{tabular}{|l|l|l|l|l|l|l|}
\hline & $\mathrm{N}$ & Mean & $\begin{array}{l}\text { Std. } \\
\text { Deviation }\end{array}$ & t-statistic & $\mathrm{df}$ & $\mathrm{p}$-value \\
\hline $\begin{array}{l}\text { With Personal } \\
\text { Computers }\end{array}$ & 152 & 24.2500 & 3.16699 & 2.817 & 278 & .005 \\
$\begin{array}{l}\text { Without Personal } \\
\text { Computer }\end{array}$ & 128 & 23.2656 & 2.57940 & & \\
\hline
\end{tabular}

Table 3. Relationship between Field of study and attitudes towards digital media approach

\begin{tabular}{|l|l|l|l|l|l|l|}
\hline & $\mathrm{N}$ & Mean & $\begin{array}{l}\text { Std. } \\
\text { Deviation }\end{array}$ & $\begin{array}{l}\text { t-statisti } \\
\mathrm{c}\end{array}$ & $\mathrm{df}$ & $\mathrm{p}$-value \\
\hline $\begin{array}{l}\text { Courses involving use } \\
\text { of computers }\end{array}$ & 140 & 17.9143 & 3.74259 & & & \\
\\
$\begin{array}{l}\text { Courses do not } \\
\text { involve use of } \\
\text { computers }\end{array}$
\end{tabular}

Table 4. Relationship between having previous computer hands-on experience and attitudes towards digital media approach

\begin{tabular}{|l|l|l|l|l|l|l|}
\hline & $\mathrm{N}$ & Mean & $\begin{array}{l}\text { Std. } \\
\text { Deviation }\end{array}$ & t-statistic & $\mathrm{df}$ & p-value \\
\hline $\begin{array}{l}\text { With previous computer } \\
\text { hands-on experience }\end{array}$ & 75 & 21.2933 & 5.56964 & & & \\
$\begin{array}{l}\text { Without previous computer } \\
\text { hands-on experience }\end{array}$ & 205 & 17.9073 & 4.44092 & 5.263 & 278 & .000 \\
\hline
\end{tabular}

